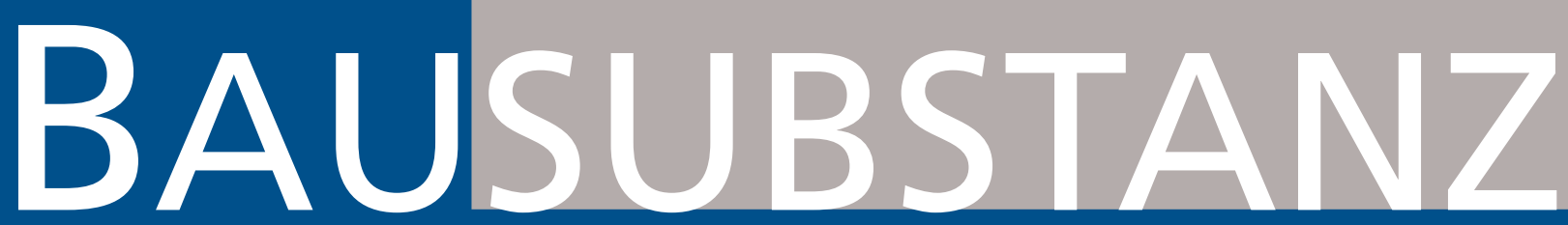

Zeitschrift für nachhaltiges Bauen, Bauwerkserhaltung und Denkmalpflege

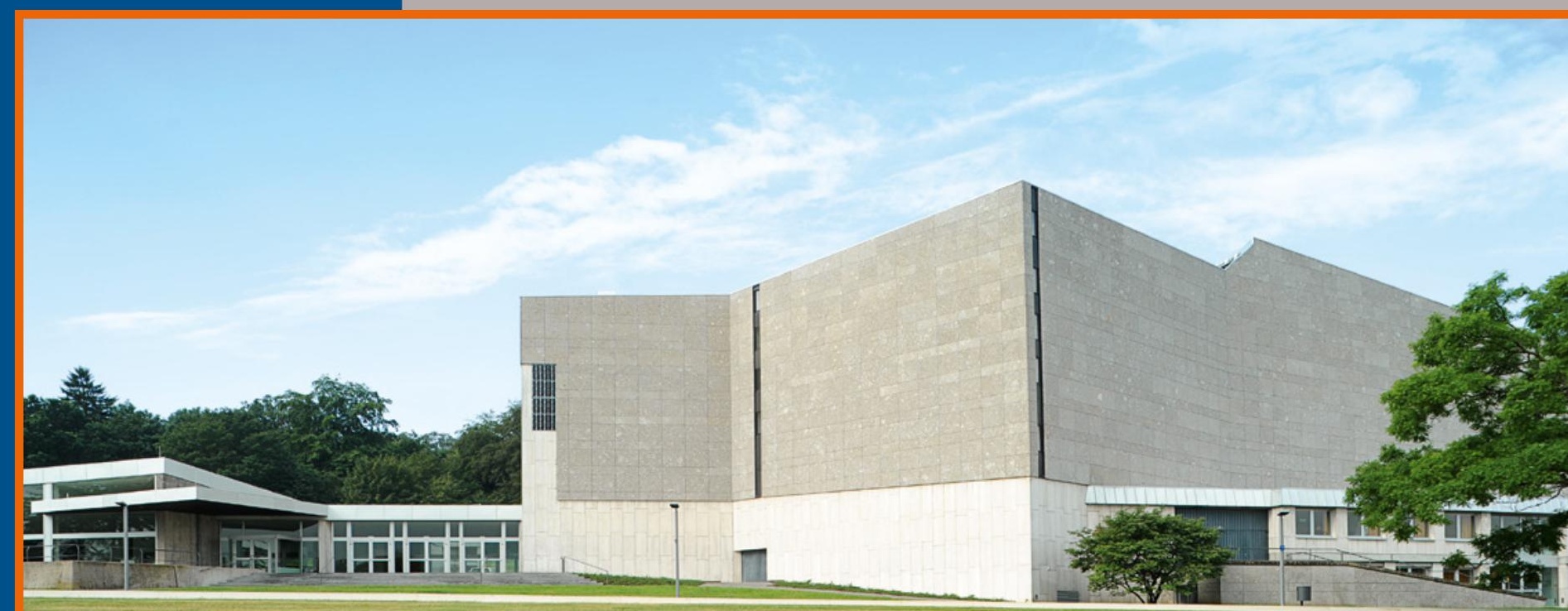

THEMA

Flugdach - Faltwerk - Fertigteile

Der bauliche Umgang mit Denkmalen der 1950er- bis 1980er-Jahre 


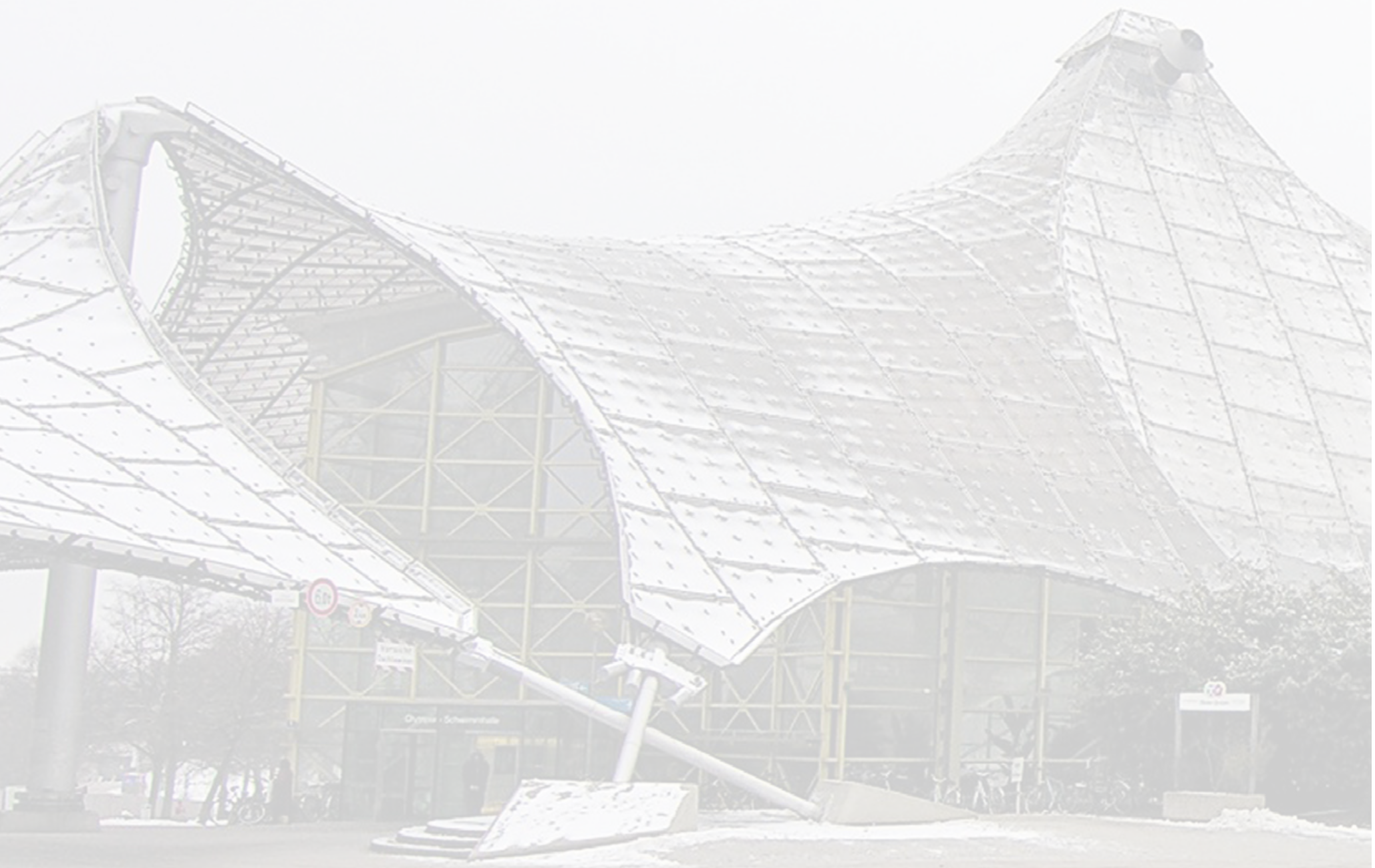



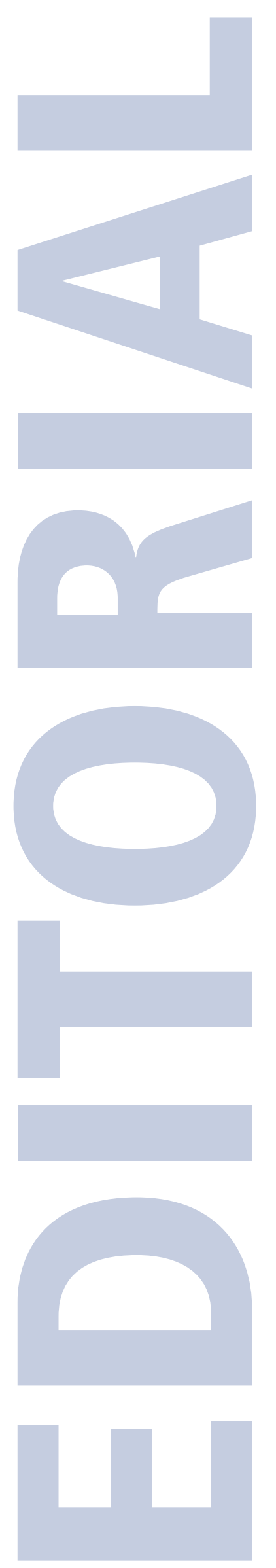

\section{Liebe Leserinnen, liebe Leser,}

D as architektonische Erbe der drei Jahrzehnte nach dem Zweiten Weltkrieg in Deutschland ist vom Wiederaufbau und vom Wirtschaftswunder geprägt sowie von der Idee eines humanistischen Sozialismus einerseits und kapitalistischer Freiheit des Individuums andererseits. Die Architekten ließen sich vom Fortschritt und einer Technikeuphorie inspirieren. Das Bauen wurde durch neue Materialien, Konstruktionsformen und Gestaltungen geprägt. In der frühen Nachkriegsmoderne entstanden schlanke, materialsparende Konstruktionen, oft mit einem hohen Glasanteil der Fassaden. Später folgten Skelettkonstruktionen mit vielfältigen Formen von Vorhangfassaden und Betonbauten, die mit der Wirkung ihrer geschalten Oberflächen spielten.

Die Ideen waren neu und die Euphorie groß, aber mangelnde Erfahrung mit den Baukonstruktionen und unzureichend erprobte Materialien lassen die Erhaltung dieser Bauten heute zu einer großen Herausforderung werden. Jahrzehntelange Vernachlässigung und eine Bauweise, die nicht auf Energieeinsparung bedacht sein musste, erschwert die langfristige Nutzung dieser erhaltenswerten historischen Gebäude. Die besonderen Konstruktionen und verwendeten Baumaterialien lassen die Erhaltung der bauzeitlichen Substanz bei einer Sanierung häufig nicht zu. Denkmalpfleger und Architekten stellen sich daher die Frage, ob ein Denkmal seinen Wert behält, obwohl ein Großteil seiner Substanz bei der Instandsetzung ausgetauscht werden musste.

Der vorliegenden Band entstand in der Folge eines gemeinsam von der WTA-Deutschland, der Arbeitsgruppe Bautechnik der Vereinigung der Landesdenkmalpfleger (VDL) sowie dem Fraunhofer IRB veranstalteten eintägigen Kongresses auf der Denkmalmesse 2018 in Leipzig. Er beschäftigt sich mit der Herangehensweise an eine denkmalverträgliche Planung für die stiltypischen Bauformen und Baustoffe und mit der Möglichkeit der Wahrung der Authentizität der Gebäude.

Die Beiträge bieten anhand unterschiedlicher Bauwerke einen guten Überblick über die Wesenszüge dieser Architektur. Dabei wird ein Einblick in Regelwerke, in die technischen Möglichkeiten der Instandsetzung sowie in bauphysikalische und konstruktive Themen gegeben. Auch Fragestellungen der bauphysikalischen/energetischen Sanierung, Möglichkeiten des Brandschutzes für filigrane Bauteile sowie der Umgang mit Schadstoffbelastungen werden behandelt. Der Band schließt mit Beiträgen, die dem Zusammenhang zwischen wissenschaftlichen Voruntersuchungen und denkmalfachlichen Fragestellungen nachgehen, die Grundlage denkmalgerechter Konzepte sind.

Ruth Klawun, Landesdenkmalamt Berlin

Frank Eßmann, tha - Ingenieurbüro Eßmann 

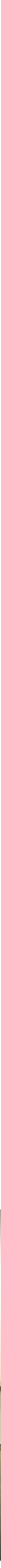

Titelbild: @ Brenne Architekten

Rolf P. Giele

Denkmalgerechte Instandsetzung historischer Stahlbetonbauwerke Regelwerke und technische Möglichkeiten

Felix Wellnitz

Baudenkmale der (Nachkriegs-)Moderne und ihre bauphysikalischen Herausforderungen

\section{Christian Scherer}

Böse Überraschungen bei der Sanierung: problematische Baustoffe aus den 1950er- bis 1980er-Jahren

Gerd Geburtig

Angemessener Brandschutz ist möglich das Scharoun Theater in Wolfsburg nach der Sanierung

Achim Pilz

\section{Scharoun Theater Wolfsburg}

Sanierung und Erweiterung eines Kulturdenkmals 
Rupert Schreiber

Verankerungen von

Natursteinvorhangfassaden

60

Roswitha Kaiser

Keramikverkleidung - der letzte Chic

64

Dorothee Heinzelmann

Instandsetzung mit Textilbeton

am Beispiel der Wallfahrtskirche

in Neviges

Julia Ludwar

Weniger ist nicht immer mehr

Betoninstandsetzung mit besonderen

Anforderungen am Beispiel der

Olympiaschwimmhalle München

Ulrike Hübner-Grötzsch

"Ostmoderne wie aus dem Ei gepellt»

Möglichkeiten der Denkmalpflege bei der

Sanierung des Kulturpalastes Dresden 80

76

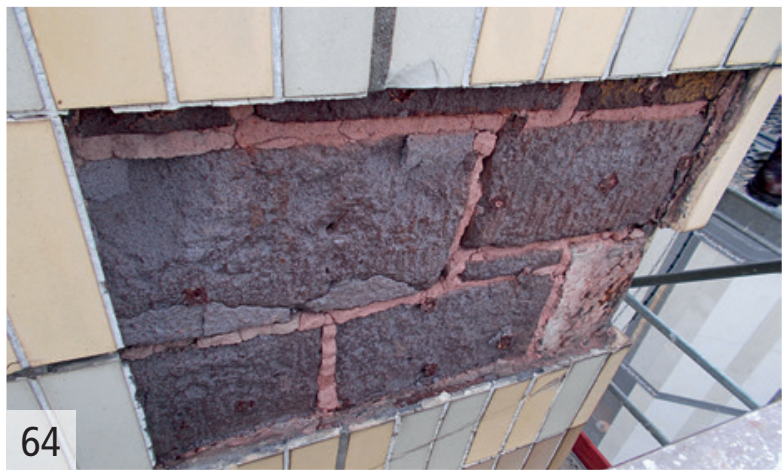

68
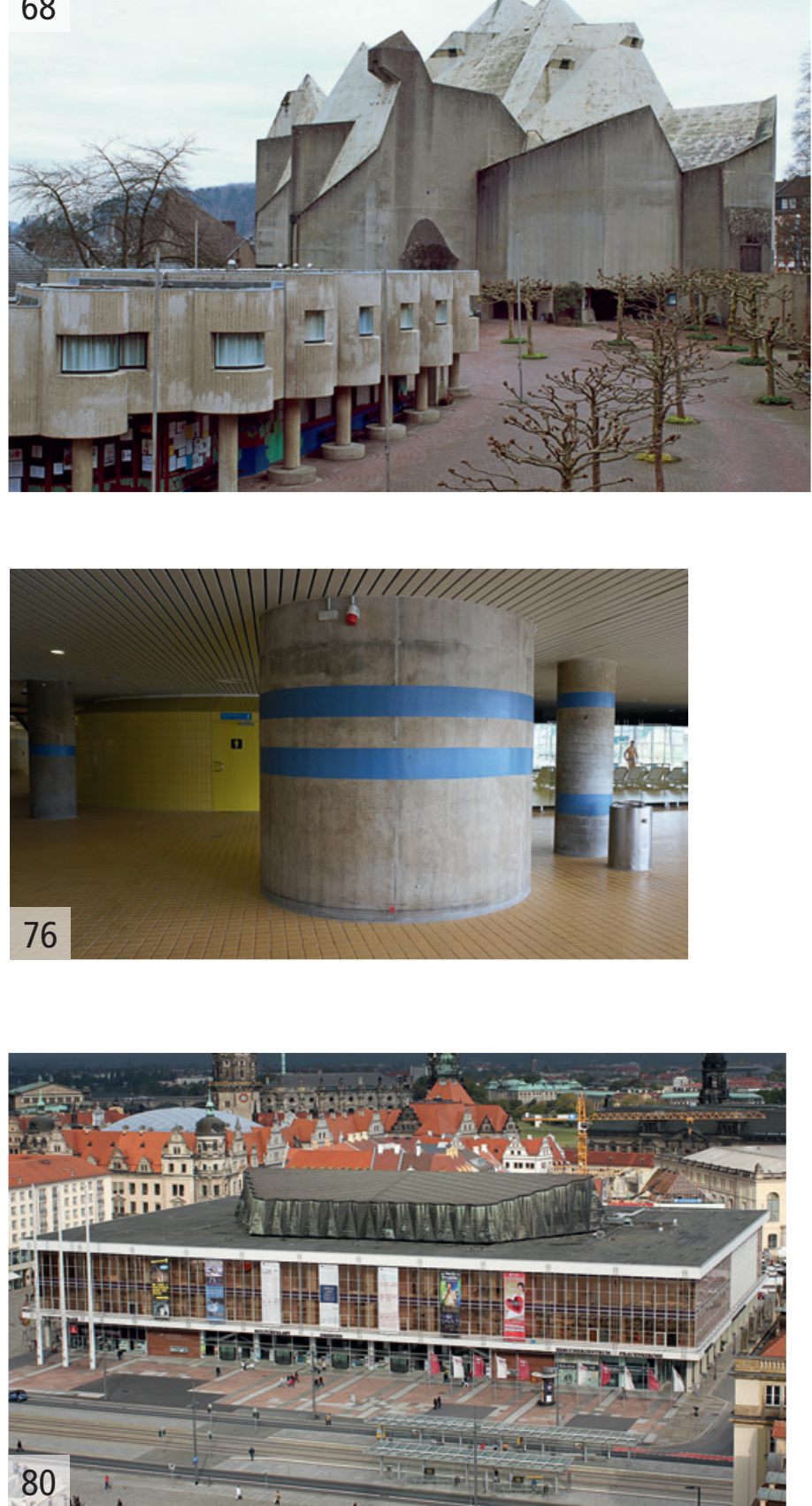